\title{
EL “DEBER SER” EN LA ORATORIA SAGRADA RIOPLATENSE (SIGLOS XVIII Y XIX)
}

\author{
Silvano G. A. Benito Moya (Coord.)*
}

Recibido: 10/05/2016 // Aceptado: 16/09/2016

\section{Introducción}

Los sermones, que está muy bien diferenciarlos de las homilías ${ }^{1}$, eran constructos discursivos complejos, que implicaban toda una maquinaria de producción. Su composición, si bien no era del patrimonio exclusivo de la Iglesia católica y, las Iglesias reformadas recurrieron a ellos en sus prácticas evangelizadoras, lo cierto es que donde alcanzaron mayor desarrollo, elocuencia y teatralidad fue dentro del seno católico postridentino (Orozco, 1980; Velandia Onofre, 2012), al punto de considerárselos como un género literario, sobre todo a los compuestos en el Siglo de Oro Español (Cerdán, 2002).

Por lo usual siempre se escribían, pues eran más extensos que una homilía y podían versar sobre temas más amplios que explicar el fragmento del Evangelio de la misa dominical, pues en las misas diarias raramente se predicaba. No obstante, pequeños apuntes para una homilía solían ser disparadores para futuros sermones. Generalmente se componían para fiestas litúrgicas solemnes, o para efemérides importantes, donde lo religioso, civil o militar estaban profundamente imbricados. Por ejemplo, no faltaban en tiempos penitenciales, tales como la Cuaresma, Semana Santa o el Adviento, donde particularmente la Iglesia mandaba predicar; siempre estaban para las fiestas solemnes como Pascua, Corpus Christi, o las de la Virgen; pero también para los "ritos de pasaje" en el seno del clero y el monacato femenino como las tomas de hábito, profesiones solemnes o renovaciones de votos; sin olvidarnos de las visitas canónicas conventuales y parroquiales, para sendos cleros. En el plano civil, para el período colonial, se componían para un onomástico del rey o su cumpleaños; el ascenso al trono; el nacimiento de algún infante, o la muerte real -en forma de oración fúnebre-, o también, igualmente civil, para la fiesta de alguna cofradía, en el peldaño más bajo de la pirámide administrativa. En

1 Era, propiamente, un proceso catequético de explicación del fragmento del Evangelio del día en el calendario litúrgico, que el celebrante podía hacerla o no durante la misa. Generalmente, el espacio para su elocución era después del primer Evangelio -que era móvil, pues cambiaba a diario durante el año litúrgico-, o bien, al final de la misa, después del segundo Evangelio -que era fijo, pues siempre eran los primeros versículos del Evangelio de San Juan-.

* Dr. en Historia. Centro de Estudios Históricos "Prof. Carlos S. A. Segreti" - Unidad asociada a CONICET - Universidad Nacional de Córdoba - Universidad Católica de Córdoba. scribalatino_ar@yahoo.com.ar 
el plano militar se componían siempre para celebrar alguna victoria, así se hicieron en profusión para el triunfo contra la invasión inglesa de 1806-07. Luego del proceso de la Revolución por la independencia, se recurrió a ellos para celebrar los triunfos bélicos revolucionarios (Martínez de Sánchez y Clissa, 2010a; Berdini 2013).

En la mayoría de los casos encerraban aspectos ejemplarizantes, a través de los cuales la Iglesia enseñaba y amonestaba en base a la moral tridentina, donde se presentaban los paradigmas ideales del "deber ser" de un cristiano: la Virgen y los santos y santas, personajes que, en cuanto a humanos, habían logrado alcanzar la perfección en el camino señalado por Dios. Se presentaban modelos de identidad, frente a situaciones reales que, en un vaivén entre lo inmediato y lo mediato, sugerían modos de comportamiento pautados, pero no siempre cumplidos.

El proceso de alimentación y composición del texto era la propia realidad de los feligreses, o bien observada por el concionador, o bien recogida a través del confesionario (Martínez de Sánchez, 2013b). No obstante, siempre estaba la recurrencia a las enseñanzas librescas, que partían de la propia retórica clásica de cómo debía componerse y cuáles serían sus partes, hasta verdaderas colecciones de sermones, que para diferentes fiestas habían compuesto o editado varios concionadores famosos y populares para la época, tenidos como columnas de cómo debía ser un buen sermón (Benito Moya, 2008).

Todas estas piezas oratorias: panegíricos, oraciones, pláticas o bien "sermones", ayudaban a construir arquetipos modélicos, pues exponían qué y cómo se debía ser en la sociedad colonial y postcolonial rioplatense que, por cierto, más allá de los matices locales no estaban ajenos al discurso universal de la Iglesia española tridentina, que traspasaba, incluso, los procesos independentistas.

Los arquetipos de ese "deber ser" eran de dirección individual o colectiva, contrapuestos al "ser" observado en el mundo que, por lo general era reconvenido y direccionado hacia lo que se pretendía que se fuera, conforme a unos parámetros que eran operativos para un proyecto social adscripto a un modo de poder. Fue necesario conectar el análisis fontal con el entramado social y cultural de la época, en el espacio seleccionado, el que estuvo inserto en una realidad regional que es parte de una amplia y matizada América Meridional.

El dossier que presentamos lleva el mismo título que el proyecto colectivo que estuvo bajo mi dirección entre 2015 y 2016, aprobado y subsidiado por la Secretaría de Ciencia y Técnica de la Universidad Nacional de Córdoba. La mayoría de los trabajos son el resultado de la investigación bianual de los miembros del equipo, junto al de una invitada: Denise Reyna Berrotarán. Sin embargo, el equipo trabaja regularmente la temática desde 2006, lo que ha dado lugar a una frondosa producción que reseñamos completa en el apartado de la bibliografía ${ }^{2}$. Debemos decir que antes de esa fecha el

2 El proyecto "En torno a la oratoria sagrada. Oralidad y escritura en sermones coloniales", que se desarrolló en los bienios 2006-2007 y 2008- 2009 estuvo bajo la dirección de Ana María Martínez de Sánchez y el equipo compuesto por Silvano G. A. Benito Moya, Julieta Consigli, Karina Clissa, Alejandra Bustos Posse y Norma C. Fenoglio. El grupo en el bienio 2010-2011 estuvo dirigido por K. Clissa e integrado 
tema, que había tenido una importante producción principalmente en España y México (Zaragoza, 2008), poco había interesado a los historiadores argentinos, que sepamos unos contados trabajos componían ese acervo (Rípodas Ardanaz, 1986; Mariluz Urquijo, 1998, 2006, 2008; Ayrolo, 2009).

La mayoría de las fuentes concionatorias que han alimentado esta investigación se encuentran en la colección documental "Mons. Dr. Pablo Cabrera", de la Facultad de Filosofía y Humanidades de la Universidad Nacional de Córdoba, y componen 305 unidades documentales. A partir de 2012, incorporamos para su estudio fuentes éditas de autores rioplatenses, tales como la colección de sermones del franciscano Pantaleón García, quien fuera rector de la Universidad de Córdoba durante la administración franciscana. La colección se publicó en Madrid en 1810 y se compone de once volúmenes ${ }^{3}$. También, desde ese año, empezamos a consultar y a estudiar de forma más sistemática y analítica la colección de sermones que se encuentra en el Archivo del Arzobispado de Córdoba y que perteneciera al Convento Grande de San Jorge (franciscanos) de la ciudad de Córdoba. Estos han sido los corpora principales que han concitado toda nuestra atención desde 2006, sin dejar de lado otros sermones éditos e inéditos consultados en otros archivos y colecciones documentales, que pueden verse citados en los trabajos de este dossier.

A los fines de hacer una línea cronológica sobre las temáticas y los intereses que el equipo ha tenido en estos años, diremos que durante el bienio 2006-2007 el grupo se abocó al estudio de los sermones sobre Ánimas del Purgatorio y los de Confesión, por constituir un corpus cuyos discursos eran más de carácter amonestador. En 2008 y 2009 seguimos en esa línea exhortativa y estudiamos los de Cuaresma y Semana Santa, aunque agregamos los de Corpus Christi, de temática festiva y discursivamente diferentes. 2010 y 2011 Bicentenario de la Revolución de Mayo, fue el espacio propicio o la excusa contextual, para estudiar los llamados "sermones patrios", constructos discursivos de los que se valió la revolución por la independencia, con el indudable apoyo de la Iglesia, para inculcar en la feligresía -incipiente ciudadanía- los valores republicanos y del nuevo orden que se instauraba. A partir de 2012 y 2013 el objetivo del equipo fue estudiar los sermones marianos referidos a las diversas advocaciones de la Virgen María. Fue allí que empezamos a trabajar los modelos de mujer que se propiciaban desde el púlpito para la niña y para la mujer adulta. Aspectos del "deber ser" femenino del siglo XVIII hasta la primera mitad del siglo XIX, permitieron profundizar en la conformación de ciertas identidades. En este último aspecto los análisis mexicanos fueron imprescindibles de considerar, por la unión que presentaba la devoción a la Virgen de Guadalupe con la constitución de la nacionalidad mexicana.

por A. M. Martínez de Sánchez, J. Consigli, N. Fenoglio, Mateo Paganini, Javier Berdini y Mariela Contreras, congregados "En torno a la oratoria sagrada. Oralidad y escritura en sermones postcoloniales". En 2012-2013, el mismo equipo estuvo dirigido por A. M. Martínez de Sánchez y S. Benito Moya sobre la temática "La oratoria sagrada y la construcción de identidades".

3 Pataleón García 1810. Sermones panegíricos de varios misterios, festividades y santos. Madrid: Imprenta de Collado, 11 vols. 
El dossier que presentamos, producto de la investigación del bienio 2015-2016, es un trabajo fontal de relectura de todo el corpus que habíamos estudiado, fraccionado por temáticas y por acervos documentales a través de todos estos años, e intentar acercarnos a ellos desde la propuesta del "deber ser", es decir desde la construcción de arquetipos modélicos que se proponían desde el púlpito u otros estrados, ya que un sermón no tenía siempre como referencia el interior de un templo para su elocución, sino también un atrio, o una plaza, o un espacio campestre, como bajo la sombra de un árbol añoso.

Karina Clissa se ocupa de cómo se presenta al niño y la infancia en los sermones; a Ana María Martínez y a mi nos ha interesado el modelo de religiosa y religioso que se pretendía imponer; a Javier A. Berdini la imagen del rey; en tanto que a Denise Reyna Berrotarán el "deber ser nacional" y el "deber ser ciudadano" en la sermonística del presbítero Pablo Cabrera.

El rol de los niños en la sociedad colonial y finicolonial es la preocupación de Karina Clissa en La oratoria sagrada y la imagen ideal de la infancia, una temática que ha tenido en los últimos años un crecimiento importante ligado a los estudios sobre la familia. En un trabajo anterior (2014) ha hecho un interesante aporte sobre el modelo femenino en los sermones marianos.

Las fuentes usadas por la autora van desde los sermones manuscritos hasta los sermones éditos, estos últimos, en diferentes tomos publicados por Fray Pantaleón García. Los interrogantes propuestos por la autora tales como "¿Cuáles son las imágenes y narrativas que hacían a la construcción social de la infancia en tales piezas oratorias? ¿Cuál era la visión de la infancia que la Iglesia dejaba traslucir a través de la predicación? ¿Cuál era la representación cultural de los sentimientos que los niños generaban en el entorno social?" Son vertebradores de su trabajo. Advierte sobre la dificultad de ocuparse de la temática por la poca visibilidad de los niños en la misma sociedad, por lo que las referencias fontales son tangenciales.

Virtudes como la inocencia de la niñez, o la obediencia que no cuestiona, o la espontaneidad son cualidades que los niños deben cultivar, pero como bien nos dice Clissa, muchas veces son usadas para que los adultos se tornen niños a los ojos de Dios.

El discurso prescriptivo buscaba formar arquetipos sociales de la familia nuclear, de naturaleza patriarcal: padre-madre-hijo, por lo que la elocución apuntaba, sobre todo, a como debía ser la educación cristiana de los hijos en el seno familiar. Si bien la férrea concepción educativa contemplaba el amor y la voluntad, sin embargo se advertía que no se debían sobrepasar los límites. Dos niños ejemplares eran puestos sobre cualquier otro: la Virgen Niña y el Niño Dios, cultos que la Iglesia propició después del Concilio de Trento.

Ana María Martínez de Sánchez en su contribución La clausura: morada perpetua trabaja la construcción del modelo femenino predicado, que tenía por finalidad ratificar la decisión de las jóvenes que ingresaban a los conventos, en este caso la ciudad de Córdoba y Buenos Aires. A través del periplo de los textos que transitan por la toma de hábitos, profesión y renovación de votos los concionadores proponían el ejercicio 
de las ventajas para la vida eterna que implican la pobreza, la castidad, la obediencia y la clausura, pensada esta última como el paraíso en la tierra, como una mansión de paz y confianza que las aislaba de un mundo que se lo veía lleno de maldades. De todo este estado se muestran los aspectos negativos y los positivos, intentando justificarse los primeros; por ejemplo, la obediencia a la prelada es el voto más difícil de cumplir, pero se lo justifica en que en la imitación de las virtudes de la superiora se alcanzará la perfección, o en que mediante la humillación se aplacará el amor propio. La pobreza es la imitación de la desnudez de Cristo y el alejamiento de los placeres mundanos, la castidad. Se insiste mucho en la clausura pues será la morada perpetua, la que las protegerá del afuera, que si bien pueden asaltarlas en algunos momentos pensamientos mundanos, luego la paz, el sosiego, el silencio de los claustros las atraerán de nuevo al paraíso elegido. Entre las imágenes positivas del claustro estaban el descanso, la felicidad y la despreocupación.

Entre las imágenes femeninas a imitar cuando novicias o profesas estaba, en primer lugar, la Virgen y luego las principales santas del calendario cristiano, sobre todo santa Catalina de Siena y Teresa de Jesús, humanas como las postulantes. No se dejan de lado mujeres famosas de la América que, aunque no habían subido todavía a los altares, sin embargo debían tener mucha notoriedad en los claustros femeninos, tales como Mariana de Quito.

Como bien señala Martínez de Sánchez respecto a la eterna morada terrenal, que "el gran eje de la predicación es que esa muerte es la victoria, porque mueren anticipadamente por propia voluntad para alcanzar de modo menos perturbador, la salvación eterna".

La preocupación del director Silvano G. A. Benito Moya como tema individual, giró en torno a la reforma de la disciplina eclesiástica legislada por Trento y cómo se plasmó a través de los sermones destinados a los religiosos. Así en Imágenes del "deber ser" del religioso, según la oratoria sagrada rioplatense, se propone que si el nuevo desafío era la evangelización, los agentes debían responder a un patrón común, que con algunas variantes en cada época se mantuvo vigente hasta entrado el siglo XIX.

Los sermones analizados son de las órdenes franciscana y dominica, para la toma de hábito y para profesiones, aunque también los hay de algunos santos caros a las órdenes como Francisco de Asís, Francisco Solano y Benito para los franciscanos y Domingo para los dominicos, que proponen modelos de virtud en el religioso.

A través de temas recurrentes como los votos de pobreza, castidad y obediencia -únicos que pronunciaban los frailes de las órdenes estudiadas-, se propone estudiar cómo la experiencia vivida en el seno del convento, en las noticias provinciales o en el confesionario servían al padre predicador para componer su sermón, en idéntico balance con la literatura libresca. Así compara a lo largo del trabajo el aspecto discursivo con la realidad histórica del modelo conventual.

Javier A. Berdini en Santos reyes. Virtuosos incas. Antiguos tiranos: imagen de la monarquía en la homilética sagrada rioplatense (sS. XVIII - XIX) analiza qué imagen de la monarquía se predicaba en general y el conjunto de ideas, nociones y creencias 
que sobre la figura de los monarcas españoles en particular (rey, reina, príncipe) se construyeron durante los períodos tardo-virreinal y revolucionario. Trabaja primero la figura del rey ausente, que será sacralizado mediante todo un aparato político, donde el sermón no estaba ausente, convertido en un instrumento propagandístico que permitía la cohesión social entre el trono y el altar. El rey será presentado como un padre para la patria y la religión y los ejemplos recurridos serán los reyes del Antiguo Testamento que habían conducido sabiamente al pueblo de Dios.

Apartir de la Revolución de Mayo, los sermones continuaron siendo usados como instrumentos propagandísticos del nuevo régimen. En lo que se escribía se empezaron a advertir tres momentos: la etapa precolombina, la española y la revolucionaria. La comparación se hace innegable, pues aparecen los mansos reyes aborígenes opuestos a la tiranía de los reyes españoles. El rey hispano será denostado como una forma de buscar adhesiones. Como bien lo dice Berdini que "esos recursos debían demostrar que los reyes 'santos' ya no lo eran y que, por el contrario, todo lo que hicieron, particularmente en América, fue negativo y repudiable".

Denise Reyna Berrotarán, toma algunos sermones y discursos de un reconocido personaje cordobés del entresiglos del XIX y XX en Monseñor Pablo Cabrera, el "deber ser nacional" y el "deber ser ciudadano" en sus sermones. Las piezas concionatorias elegidas pertenecen a la primera etapa en la vida de Cabrera (1857-1936), en sus primeros años como orador sagrado, ya que en palabras propias del sacerdote, por un problema en las cuerdas vocales debió abandonar el oficio concionador, convirtiéndose en un importante historiador cordobés de la etapa de profesionalización de la historia. Para Cabrera el ser "buen cristiano" es equivalente a ser "buen ciudadano".

Con el análisis de un sermón de Te Deum por el feliz suceso de la firma de los Pactos de Paz entre Chile y Argentina en 1902 en la catedral de Buenos Aires y el de un 25 de Mayo del mismo año, Berrotarán estudia las pautas para la nación y el deber ser de los ciudadanos. Los sermones de Cabera se pronunciaron en medio de un proceso de romanización de la Iglesia que, en medio de las luchas entre católicos y liberales, se veía como capital una cristianización de la sociedad.

Los sermones, como fuente textual, son un aporte valioso para el estudio social porque permiten avanzar sobre aspectos que fueron considerados como un segmento especial de la Historia de la Iglesia, y que hoy se incorpora como parte de un análisis pluricausal e interrelacionado. Quienes los escribían y decían, y quienes los escuchaban, formaban parte de una sociedad compartida. El discurso reflejaba necesariamente la realidad y, a su vez, esta espejaba los textos, fuera en sus fidelidades o en sus transgresiones. 


\section{Referencias bibliográficas}

La bibliografía no refleja solo la utilizada en la introducción, sino la producción del equipo entre 2008 y 2015.

Ayrolo, V. 2009. "El sermón como instrumento de intermediación cultural. Sermones del federalismo cordobés, 1815- 1852". Nuevo Mundo Mundos Nuevos, Debates. Recuperado de: http://nuevomundo.revues.org/index57521. html.

Benito Moya, S. G. A. 2008. "In principio erat verbum. La escritura y la palabra en el proceso de producción del sermón hispanoamericano”. En: A. M. Martínez de Sánchez (comp.), Oralidad y escritura. Prácticas de la palabra: los sermones. Córdoba: Programa de Estudios Indianos, Centro de Estudios Avanzados, Universidad Nacional de Córdoba, pp. 71-95.

Benito Moya, S. G. A. 2014a. "La oralidad sobre el papel. Un tipo documental típico de los archivos eclesiásticos: el sermón”. En: J. Vassallo y N. García (comps.). Aportes para pensar la Archivología en el siglo XXI, desde la investigación, la extensión y la práctica. Córdoba: Universidad Nacional de Córdoba, 2014, pp. 94-106.

Benito Moya, S. G. A.; Martínez de Sánchez, A. M.; Consigli, J.; Paganini, M.; Berdini, J. A.; Fenoglio, N. C. 2014b. "El valor de la palabra en textos pastorales coloniales y postcoloniales”. En: J. Vassallo y L. Pereyra (comps.). La Facultad de Filosofía en Cuatrociencia. Experiencias y saberes compartidos. Córdoba: Universidad Nacional de Córdoba, 2014, pp. 53-57. Recuperado de: http://www.ffyh.unc.edu. ar/editorial/e-books/.

Berdini, J. A. 2013. "Sermones, batallas y victorias: providencialismo y patrocinio guerrero de la Virgen María en la homilética sagrada (1806-1812)". A. M. Martínez de Sánchez (dir.) Cátedra, púlpito y confesionario. Hacer y decir los sermones. Córdoba: CIECS, pp. 75-99.

Berdini, J. A. 2014. "América, espejo de Grecia y Roma: Tradición clásica en el púlpito rioplatense (siglos XVIII-XIX)”. En: A. M. Martínez de Sánchez Algunos sujetos y objetos de la oratoria sagrada en América colonial. Córdoba: CIECS, pp. $33-$ 52. Recuperado de: http://hdl.handle.net/11086/1706.

Berdini, J. A. 2015. "Memoria genealógica de los linajes Tejeda y Cabrera en sermones de fray Pantaleón García (Córdoba, siglo XVIII)". En: Anuario de la Academia Argentina de Genealogía y Heráldica, 43, Córdoba: Academia Argentina de Genealogía y Heráldica, pp. 121-137.

Cerdán, F. 2002. “Actualidad de los estudios sobre oratoria sagrada del Siglo de Oro (1985-2002). Balance y perspectivas”. Criticón, 84-85, 2002, pp. 87-105.

Clissa, K. 2008. "El valor de la confesión en sermones coloniales". En: A. M. Martínez de Sánchez (comp.), Oralidad y escritura. Prácticas de la palabra: los sermones. Córdoba: Programa de Estudios Indianos, Centro de Estudios Avanzados, Universidad Nacional de Córdoba, pp. 97-118. 
Clissa, K. 2013. "Lo humano y lo divino. Argumentos sobre el 'deber ser". A. M. Martínez de Sánchez (dir.) Cátedra, púlpito y confesionario. Hacer y decir los sermones. Córdoba: CIECS, pp. 31-53.

Clissa, K. 2014. "El modelo mariano en la palabra de los concionadores". En: A. M. Martínez de Sánchez Algunos sujetos y objetos de la oratoria sagrada en América colonial. Córdoba: CIECS, pp. 53-76. Recuperado de: http://hdl.handle. net/11086/1706.

Consigli, J. M. 2008. "Citas latinas en sermones coloniales de confesión y de ánimas". En: A. M. Martínez de Sánchez (comp.), Oralidad y escritura. Prácticas de la palabra: los sermones. Córdoba: Programa de Estudios Indianos, Centro de Estudios Avanzados, Universidad Nacional de Córdoba, pp. 143-167.

Fenoglio, N. C. 2014. "Normas internacionales y particulares para la descripción de documentos de creación”. En: A. M. Martínez de Sánchez Algunos sujetos y objetos de la oratoria sagrada en América colonial. Córdoba: CIECS, pp. 117132. Recuperado de: http://hdl.handle.net/11086/1706.

Mariluz Urquijo, J. M. 1998. "Retórica y homilética rioplatense. Una preceptiva concionatoria dieciochesca". En: Archivum, 18, Buenos Aires, Junta de Historia Eclesiástica Argentina, pp. 147-158.

Mariluz Urquijo, J. M. 2006. "La predicación rioplatense frente al poder durante el siglo XVIII". En: Revista de Historia del Derecho, 34, Buenos Aires, Instituto de Investigaciones de Historia del Derecho, pp. 191-212.

Mariluz Urquijo, J. M. 2008. "La sociedad rioplatense del siglo XVIII a través de los sermones". Iudex et Magister. Miscelánea en honor del Pbro. Nelson C. Dellaferrera, t. I: Historia del Derecho. Buenos Aires: Pontificia Universidad Católica Argentina, pp. 287-312.

Martínez de Sánchez, A. M. comp. 2008a. Oralidad y escritura. Prácticas de la palabra: los sermones. Córdoba: Programa de Estudios Indianos, Centro de Estudios Avanzados, Universidad Nacional de Córdoba.

Martínez de Sánchez, A. M. 2008b. "El purgatorio. Visión y acción a través de los sermones de ánimas”. En: A. M. Martínez de Sánchez (comp.), Oralidad y escritura. Prácticas de la palabra: los sermones. Córdoba: Programa de Estudios Indianos, Centro de Estudios Avanzados, Universidad Nacional de Córdoba, pp. 119-141.

Martínez de Sánchez, A. M. y Consigli, J. M. 2009. "Significación de la palabra en solemnidades eucarísticas: los sermones". En: $1^{\circ}$ Congreso de historia de las Órdenes y Congregaciones Religiosas. $4^{a}$ Jornadas de Historia de la Orden Dominicana en Argentina. Tucumán: Instituto de Investigaciones Históricas Prof. Manuel García Soriano, Universidad del Norte Santo Tomás de Aquino, 2009. CDRom.

Martínez de Sánchez, A. M. y Clissa, K. 2010a. El valor de la palabra en sermones patrios. ¿Libertad o independencia? Córdoba: Centro de Estudios Avanzados, Universidad Nacional de Córdoba, 2010. 
Martínez de Sánchez, A. M. y Clissa, K. 2010b. "Voces concionadoras: ¿libertad o independencia?". Signos Universitarios, Anejo 1 de la Revista de la Universidad del Salvador. Buenos Aires: Universidad del Salvador, 2010, pp. 107-130.

Martínez de Sánchez, A. M. 2010a. "Imágenes de lo jurídico en sermones fini y postcoloniales". Revista Chilena de Historia del Derecho. Homenaje a Bernardino Bravo Lira, 22, Santiago de Chile, Universidad de Chile, pp. 543-554.

Martínez de Sánchez, A. M. 2010b. "Púlpito y cofradía. Córdoba del Tucumán en el siglo XVIII”. En: D. Lévano; K. Montoya Estrada (comps.). Corporaciones religiosas y evangelización en Iberoamérica. Siglos XVI-XVIII, Lima: Fondo Editorial de la Universidad Nacional Mayor de San Marcos, pp. 61-88.

Martínez de Sánchez, A. M. 2011. "Orality and Scripture: Sermons as a Means of Communication in the Eighteenth and Nineteenth Centuries". En: A. Windus y E. Crailsheim (eds.). Image-Object-Performance: Mediality and Communication in Early Modern Contact Zones of Latin America and the Philippines, Münster: Universität Hamburg - Waxmann, pp. 121-140.

Martínez de Sánchez, A. M. dir. 2013a. Cátedra, púlpito y confesionario. Hacer y decir los sermones. Córdoba: CIECS.

Martínez de Sánchez, A. M. 2013b. "Púlpito y confesionario: los espacios de la persuasión”. En: A. M. Martínez de Sánchez (dir.). Cátedra, púlpito y confesionario. Hacer y decir los sermones. Córdoba: CIECS, pp. 9-30.

Martínez de Sánchez, A. M. 2014. Algunos sujetos y objetos de la oratoria sagrada en América colonial. Córdoba: CIECS. Recuperado de: http://hdl.handle. net/11086/1706.

Martínez de Sánchez, A. M. 2015. “La Oratoria sagrada en el Tucumán”. En: R. López Guzmán; Y. Guasch Marí y G. Romero Sánchez (eds.) América: cultura visual y relaciones artísticas. Granada: Ediciones Universidad de Granada, pp. 75-84.

Orozco, E. 1980. "Sobre la teatralización del templo y la función religiosa en el barroco: el predicador y el comediante". En: Cuadernos para investigación de la literatura hispánica, 2-3, Madrid: Fundación Universitaria Española, pp. 171-188.

Paganini, M. 2013. "Los divinos simulacros de la América colonial”. A. M. Martínez de Sánchez (dir.) Cátedra, púlpito y confesionario. Hacer y decir los sermones. Córdoba: CIECS, pp. 55-73.

Rípodas Ardanaz, D. 1986. "Los sermones cuaresmales a la Audiencia de Buenos Aires y su propuesta de oidor ideal". Revista Chilena de Historia del Derecho, 12, Santiago de Chile: Centro de Investigaciones de Historia del Derecho de la Universidad de Chile, pp. 263-273.

Velandia Onofre, D. 2012. “'Teatro en el púlpito? La oratoria sagrada española del siglo XVII'. Perifrasis, 3, 5, Bogotá, pp. 35-48.

Zaragoza, V. 2008. "El sermón como fuente: una aproximación bibliográfica". En: A. M. Martínez de Sánchez (comp.), Oralidad y escritura. Prácticas de la palabra. los sermones. Córdoba: Programa de Estudios Indianos, Centro de Estudios Avanzados, Universidad Nacional de Córdoba, pp. 15-32. 